week or so, then to return to normal. For example, the least attractive of these three men suddenly became most attractive for eight days out of nine, and in this period attracted 186 o $A$. melas, while his nearest rival attracted only 77 ; during two successive days at the beginning of this period he attracted five times as many mosquitoes as either rival. Statistical analysis shows that these results are significant. De Meillon ${ }^{3}$ showed that thorough deodorization with soap and water considerably diminished attractiveness to $A$. funestus, but this factor seems insufficient to account for these results, which I consider to be due to variations in the physiological condition of the men.

It is likely that there are wide differences between the relative attractiveness of different individuals of different habits, but I know of no proved case of absolute immunity, and think that such claims are usually made by fortunate individuals who have escaped the more obvious consequences of mosquito bites and, therefore, erroneously concluded that they have never been bitten.

3 Mowbray Road,

$$
\text { C. R. Ribbands }
$$

Cambridge.

Nov. 23.

1 Bristowe, W. S., Nature, 158, 750 (1946).

'Ribbands, C. R., Bull. Ent. Res., 37, 163 (1946).

'De Meillon, B., Pub. S. Afr. Inst. Med. Res., 6, 323 (1935).

\section{Anopheline Mosquitoes as Natural Vectors of Equine Dermal Filariasis}

Papadaniel' has reported, under the name of 'gâle microfilarienne', a dermatosis affecting horses and mules in Greece. The disease is associated with the presence of microfilariæ in the skin lesions. Analogy with filariasis elsewhere would suggest that the infection is insect-borne. From the available literature it appears that the natural vectors in Greece have not previously been described.

In the course of an investigation by members of this Laboratory on malaria transmission in eastern Macedonia, developmental forms of filarial larvæ were observed in Anopheles sacharovi (var. elutus) and in A. maculipennis (var. typicus). Between July 24 and August 27, 1946, the total of mosquitoes dissected was 456, of which the majority were $A$. sacharovi and the remainder $A$. maculipennis. Filarial larvæ were found in fourteen $A$. sacharovi and in one A. maculipennis (var. typicus). The infection-rate in $A$. sacharovi was 3 per cent. The larvæ were recovered from the musculature of the mosquito thorax or neck, in numbers varying from one to eight per mosquito. In the fresh preparation, the larvæ were actively motile. The length varied from $0.9 \mathrm{~mm}$. to $2.3 \mathrm{~mm}$. and the diameter from $25 \mu$ to $55 \mu$.

In the same series of dissections high plasmodial sporozoite and oocyst rates were recorded. In two specimens of $A$. sacharovi, simultaneous infection with filarial larvæ and plasmodial oocysts was observed.

Local human inhabitants showed a high incidence of malaria but no clinical evidence of filariasis. Fresh blood preparations taken from 95 persons by day and from 69 persons by night showed no microfilariæ. In addition, 30 specimens of venous blood, examined by Fülleborn's concentration technique ${ }^{2}$, gave negative results.
Local mules were found heavily infected with microfilariæ. In this part of our investigation we were fortunate to have the assistance of Major S. Papadaniel, of the Greek Army Veterinary Corps. Examination of the exudate from skin lesions showed microfilariæ in large numbers. The length of these forms varied from $150 \mu$ to $170 \mu$ and the diameter from $3 \mu$ to $4 \mu$.

Investigations are proceeding. Full details of the work will be submitted for publication elsewhere. Our thanks are due to Major J. C. W. MacFarlane and Sgt. J. Tait for their help with the venous blood examinations.

\section{J. D. Аввотт \\ A. T. RODEN \\ M. YOELI}

No. 2 Mobile Malaria Field Laboratory, R.A.M.C.

${ }^{1}$ Papadaniel, Ann. Med. Vet. (Oct. 1936).

"Fülleborn, "Handbuch der Pathogenen Mikroorganismen", 8 (1928).

\section{Division of Labour in Ants}

MODERN work on ant behaviour has shown that there is much greater individuality between one ant and another than was supposed. There is great variation in the individual psychology of ants : in their instincts, in their powers of learning, in their experience and their degrees of reaction to stimuli (see Schneirla, Chen, et al. ${ }^{1}$ ). This individuality reaches its highest development in the Formicinæ, where the social integration is also greatest-a fact which has appeared, to some people, surprising.

The basic integrating force of the ant community is that the offspring have experience of living mothers in their midst, while they themselves are sterile. The queens thus represent the shared fertility of the workers. This factor, coupled with the emotional bond of frequent mutual regurgitation, and the psychological and physiological similarity of the individual workers of the colony, leads to a most intimate mental and physical relationship.

Thus an ant reacts very quickly to the reaction of its neighbours; and when one ant responds to a stimulus, the other ants in close proximity to it are stimulated to similar reaction unless they are already reacting to a stronger stimulus, or their response to that particular stimulus is already fully satisfied.

The gesticulatory antennal communication system is an entirely adequate method of communication for the working of this method of the division of labour. One ant feeling hunger will leave the nest and forage, exciting other workers which it meets to do the same; another ant is stimulated to undertake the building operations required in another part of the nest, and similarly attracts other ants to that operation. These initial respondants to the stimuli are termed the 'excitement centres'2.

The strength of the 'excitement centre' weakens as the operation nears completion or the reaction of the individual is satisfied, and eventually it fails completely. The operation will often be changed owing to the creation of a new stimulus: licking the larvæ may change to going out to forage if they show signs of hunger, or to moving them to a more humid chamber if they show signs of desiccation. The 'excitement centres' also function within the various operations causing the attraction and counterattraction of ants between the various centres of activity. 